\title{
Highly Chemoselective Synthesis of Hindered Amides via Cobalt-Catalyzed Intermolecular Oxidative Hydroamidation
}

Yun-Nian Yin, Rui-Qi Ding, Dong-Chen Ouyang, Qing Zhang and Rong Zhu*

Beijing National Laboratory for Molecular Sciences, Key Laboratory of Bioorganic Chemistry and Molecular Engineering of Ministry of Education, College of Chemistry and Molecular Engineering, Peking University, Beijing 100871, China

Correspondence e-mail: rongzhu@pku.edu.cn (R. Zhu)

\begin{abstract}
Tertiary amides are of great importance for medicinal chemistry. However, they are often challenging to access through conventional methods due to reactivity and chemoselectivity issues. Here we report a single-step approach towards such amides via cobalt-catalyzed intermolecular oxidative hydroamidation of unactivated alkenes, using nitriles of either solvent- or reagent-quantities. This protocol is orthogonal to groups that rapidly react under known carbocation amidation conditions such as tertiary alcohols, electron-rich alkenes, ketals, weak $\mathrm{C}-\mathrm{H}$ bonds, and carboxylic acids. Straightforward access to a diverse array of hindered amides is demonstrated, including a rapid synthesis of an aminoadamantanederived pharmaceutical intermediate.
\end{abstract}




\section{Introduction}

$\alpha$-Tertiary amine derivatives are widely found in biologically active natural products and pharmaceuticals (Scheme 1a). ${ }^{[1]}$ The extensive substitution about the $\mathrm{C}-\mathrm{N}$ bond makes such motifs highly valuable for medicinal chemistry because of the improved lipophilicity and metabolic stability. ${ }^{[2]}$ However, for the same reason, they are challenging targets synthetically. The most straightforward approach involves the addition of a carbon nucleophile to a ketimine, which often lacks adequate reactivity. ${ }^{[3]}$ Alternatively, intramolecular transformations ${ }^{[4]}$ and radical amination ${ }^{[5]}$ have been explored. It is noteworthy that many $\alpha$-tertiary amine derivatives obtained by the aforementioned methods are converted to the corresponding amides by multi-step downstream processes, while constructing such hindered amide bonds in an intermolecular setting is equally challenging. ${ }^{[6]}$ In this context, single-step approaches leading to $\alpha$-tertiary amides are highly desired.

A potential solution involves intercepting a tertiary carbocation with a nitrile, known as the Rittertype amidation (Scheme 1b). Traditionally, it requires strong Brønsted or Lewis acids for substrate activation. ${ }^{[7]}$ Recent advances highlight oxidative activation as an alternative. For example, Baran and coworkers demonstrated Ritter-type amidation initiated by $\mathrm{C}-\mathrm{H}$ abstraction or electrochemical oxidative decarboxylation. ${ }^{[8]}$ Similar processes mediated by I(III) have been reported ${ }^{[9]}$ Related trapping processes can be found in a number of alkene radical difunctionalization reactions, but mostly limited to styrenes. ${ }^{[10]}$ Nonetheless, the chemoselectivity issue remains largely unsolved, and could be further complicated by the presence of multiple weak $\mathrm{C}-\mathrm{H}$ bonds or oxidizable sites. Besides, the high energy nature of carbocation species necessitates using solvent-quantities of the nitrile nucleophile, which significantly limits the synthetic application. As a second and conceptually distinct approach, intermolecular hydroamidation via transition-metal-mediated $\pi$-bond activation has been pursued. However, for years 
limited success has been achieved with the Markovnikov-selective functionalization of unactivated olefins, and examples of $\alpha$-tertiary amide synthesis are particularly rare. ${ }^{[11]}$

\section{a) Representative Pharmaceutically Relevant $\alpha$-Tertiary Amides}<smiles>COc1cc2c(cc1Cl)C1(CCN(C(=O)[C@H]3CN(C(C)(C)C)C[C@H]3c3ccc(F)cc3F)CC1)CC2C(C)(C)NC(C)=O</smiles>

MK-0489

Melanocortin Subtype-4 Receptor Agonist

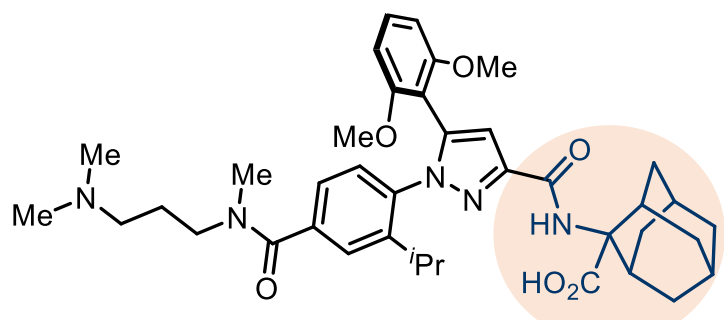

SR 142948A

Neurotensin Receptor Antagonist

b) Previous Work

Amidation via Carbocations<smiles>OC=C(O)O</smiles>

or<smiles>O=CC(O)(O)O</smiles>

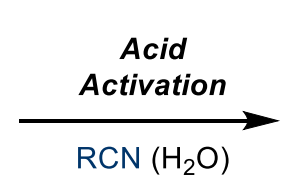

Acid

$\operatorname{RCN}\left(\mathrm{H}_{2} \mathrm{O}\right)$

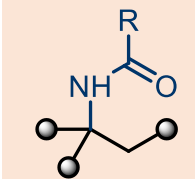

- Limited Chemoselectivity

- Solvent-Quantities of Nitrile
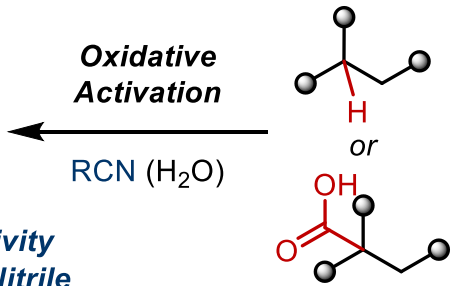

Typical Conditions:

$\mathrm{CuBr}_{2}, \mathrm{Zn}(\mathrm{OTf})_{2}$, Selectfluor or $\mathrm{HIO}_{3}, \mathrm{NHPI}$

$+\mathrm{C} /-\mathrm{C}, \mathrm{AgClO}_{4}, 2,4,6$-collidine or $\mathrm{Phl}(\mathrm{OAc})_{2}, \mathrm{I}_{2}$

Amidation via Transition-Metal-Mediated Olefin Activation

e.g.

$\mathrm{Me}_{\text {excess }}^{\mathrm{Me}}+\underset{\mathrm{H}}{\mathrm{N}_{\mathrm{H}}^{\mathrm{Me}}=0} \underset{\substack{\text { dioxane, } 100^{\circ} \mathrm{C} \\ 72 \%}}{\stackrel{\mathrm{LAuCl}, \mathrm{AgSbF}_{6}}{\longrightarrow}}$<smiles>CC(C)CN1CCN(C)C1=O</smiles>

${ }^{t} \mathrm{Bu}$
- Various Mechanisms (Au, Ir, Pd, Cu, etc.) - Difficult for Unactivated Alkenes

c) This work: Chemoselective Co-Catalyzed Oxidative Hydroamidation<smiles>O/C=C/O</smiles>

Via:

HAT

Activation
$\mathbf{R}_{\mathbf{3}} \mathrm{SiH}$

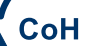

$\mathrm{RCN} / \mathrm{H}_{2} \mathrm{O}$

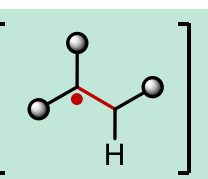
Functionalization

First general system allows for efficient intermolecular trapping of $3^{\circ}$ radicals in oxidative HAT

Orthogonal to reactive FGs:<smiles>[R]C(=O)NC(O)(O)C(O)O</smiles>

$R C N$ as either solvent or reagent:

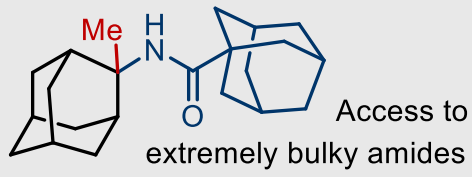

Scheme 1. Importance of $\alpha$-Tertiary Amides and Design of Cobalt-Catalyzed Oxidative Hydroamidation. 
Inspired by these achievements, we proposed a new strategy that merges the key concepts from both approaches discussed above, namely carbocation chemistry and metal-mediated olefin activation. More specifically, we hypothesized an intermolecular hydroamidation process of non-activated alkenes leveraging a hydrogen-atom-transfer (HAT)/oxidative trapping sequence (Scheme 1c). ${ }^{[12]}$ Along with the work from Mukaiyama, ${ }^{[13]}$ Carreira, ${ }^{[14]}$ Norton, ${ }^{[15]}$ Shenvi, ${ }^{[16]}$ Herzon, ${ }^{[17]}$ Shigehisa, ${ }^{[18]}$ and many others,,${ }^{[19]}$ we expected that exceptional chemoselectivity could be realized by using HAT for activation. Such a process specifically targets alkenes and should be orthogonal to functional groups that are reactive to acid or oxidation. Moreover, alkenes could be differentiated by their steric hindrance in addition to electronic natures, which enables even more precise control. The key challenge lies in the second stage. Intermolecular oxidative trapping of a tertiary alkyl radical in Co-catalyzed hydrofunctionalization reactions has been essentially unsuccessful so far, as a result of facile alkene isomerization or hydration. ${ }^{[12 a, 18 a]}$

Here we report the realization of this design by a new system featuring a combination of a CoSalen catalyst and oxone, a green oxidant. This modification successfully overcomes the tertiary radical trapping problem in previously reported systems promoted by either I(III) or $N$-fluorocollidiniums. Meanwhile, it leads to a significantly more eco- and economically friendly process. Importantly, we show that nitriles can be employed in reagent-quantities. Syntheses of a range of $\alpha$-tertiary amides are demonstrated with unprecedented chemoselectivity, including extremely hindered structures that are difficult to access otherwise.

\section{Results and Discussion}


$\underline{\text { Investigation of reaction conditions }}$

We commenced our investigation by studying the oxidative hydroamidation reaction of 2 methyldodec-1-ene (2a) in acetonitrile as the solvent (Table 1). The combination of a catalytic quantity of CoSalen complex 1a, tetramethyldisiloxane (TMDSO) as a hydride source, and oxone as a stoichiometric oxidant successfully promoted the desired transformation, affording the desired $\alpha$-tertiary acetamide 3a in over 95\% yield (entry 1). In contrast, CoSalen $\mathbf{1 b}$ bearing a less sterically bulky backbone furnished mostly isomerized alkene 4a (entry 2). As mentioned earlier, isomerization dominated when oxone was replaced by $\mathrm{N}$-fluorocollidinium salt $\mathbf{5}$, a specialized oxidant previously found particularly effective for several intramolecular transformations by Shigehisa and coworkers (entry 3). ${ }^{[18 b]}$ Interestingly, $\mathrm{KHSO}_{5}$, the active ingredient of oxone, was found much less effective by itself (entry 4). A few peroxy-containing oxidants were next tested and all found inferior (entries 5-6).

Control experiments established the essential roles of the catalysts, silane, and water, respectively (entries 7-9). In the absence of the silane, cobalt-mediated epoxidation took place and eventually furnished oxazoline 6 ( $\sim 10 \%$ yield $)$. This suggests that the hydride transfer from the silane to the oxidized cobalt species is likely rapid so that competing oxygen atom transfer can be avoided. Anhydrous conditions drove the reaction toward isomerization. Neither amidation nor isomerization was observed when oxone was substituted by $\mathrm{KHSO}_{4}$ (entry 10). In addition, the hydroamidation process was not affected by the presence of excess base (entries 11-12). Therefore, Brønsted acid-mediated amidation is unlikely involved in this system. Performing the reaction under ambient atmosphere resulted in substantially decreased yield due to oxygen trapping (entry 13). Finally, the catalyst loading could be lower to 5 mol\% without compromising the yield (entry 14). 
Table 1. Evaluation of Reaction Conditions ${ }^{a}$

\section{Standard Conditions}

$10 \mathrm{~mol} \% 1 \mathrm{a}$

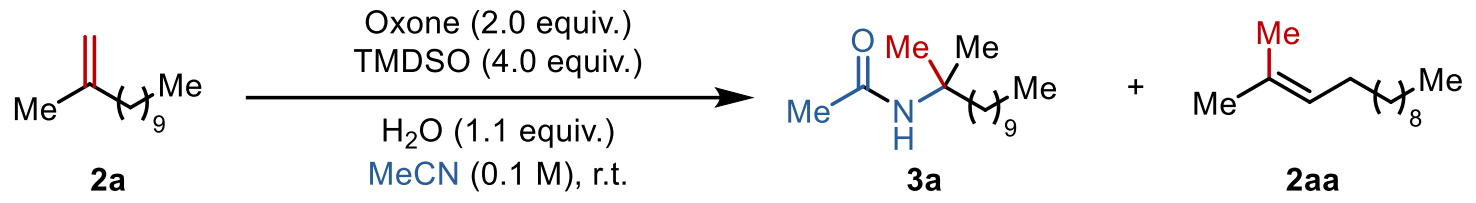

\section{Entry Changes from "Standard Conditions" $\mathbf{3 a}(\%)^{\mathrm{b}} \quad \mathbf{2 a a}(\%)^{b}$}

1

2

3

4

5

6

7

8

9

10

11

12

13

14
None

$1 \mathbf{b}$ instead of $1 \mathbf{a}$

5 instead of oxone

$\mathrm{KHSO}_{5}$ instead of oxone

TBHP instead of oxone

BPO instead of oxone

Without 1a

Without TMDSO

Without water

$\mathrm{KHSO}_{4}$ instead of oxone

With 2,6-lutidine (2.0 equiv.)

With $\mathrm{NaHCO}_{3}$ (2.0 equiv.)

Open to air

$5 \mathrm{~mol} \% \mathrm{1a}$
97

n.d.

10

68

11

52

65

$<5$

12

$<5$

$<5$

n.d. n.d.

n.d. n.d.

n.d. $\quad 60$

n.d. n.d.

$86<5$

$91<5$

26 n.d

95 n.d. 


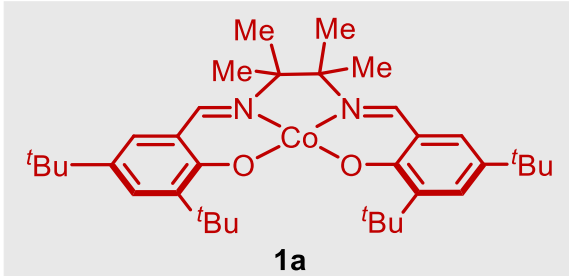

$1 a$

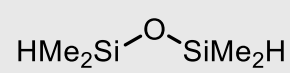

TMDSO

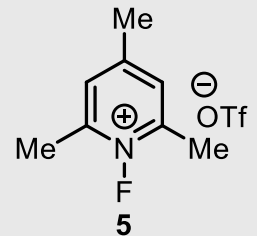

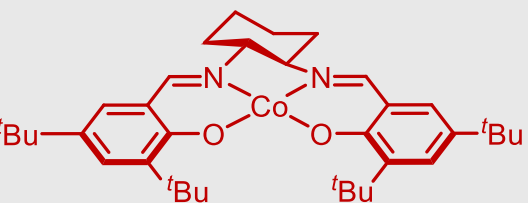

1b

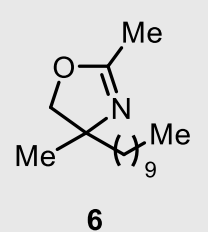

${ }^{a}$ Standard conditions: 2a $(0.1 \mathrm{mmol}), \mathbf{1 a}(10 \mathrm{~mol} \%)$, oxone (2.0 equiv.), TMDSO (4.0 equiv.), $\mathrm{H}_{2} \mathrm{O}$ (1.1 equiv.) in $1.0 \mathrm{~mL} \mathrm{MeCN}$ at r.t. for $18 \mathrm{~h} .{ }^{b}$ Determined by ${ }^{1} \mathrm{H}$ NMR analysis of the crude reaction mixture. TBHP = tert-butyl hydroperoxide. $\mathrm{BPO}=$ benzoyl peroxide.

\section{$\underline{\text { Substrate scope }}$}

With the optimized protocol in hand, we sought to evaluate the scope and limitation of this method (Scheme 2). First, the effect of alkene substitution was examined (Scheme 2a). 1,1-Dialkyl substituted olefins gave nearly quantitative yields (2a-c). Acyclic trisubstituted alkenes such as $\mathbf{4 a}$ were found unreactive, but their exo- and endo-cyclic counterparts are viable substrates (2d-f). While focusing on $\alpha$ tertiary amides synthesis, we tested monoalkyl-substituted alkenes and found them substantially less reactive $(\mathbf{2 g})$.

Next, highly chemoselective hydroamidation of terminal olefins was demonstrated, which highlights its orthogonality to groups that undergo facile Ritter-type amidation upon either acid or oxidative activation (Scheme 2b). Tertiary alcohols were well-tolerated including an admantane-1-ol (2h, i). Weak benzylic $\mathrm{C}-\mathrm{H}$ bonds associated with an electron-rich arene and carboxylic acids also remained intact during the reaction $(\mathbf{2} \mathbf{j}, \mathbf{k})$. Notably, it has been reported that $\mathbf{2} \mathbf{j}$ underwent Friedel-Crafts-type cyclization 
using $N$-fluorocollidinium 5 as an oxidant for cobalt. ${ }^{[18 e]}$ The absence of such cyclization here clearly indicates the mechanistic distinction of our newly developed CoSalen/oxone system that turns on the intermolecular trapping pathway.

The advantage of HAT activation is best illustrated by the complete selectivity for terminal alkenes (2l-2o). Tolerating a tetrasubstituted olefin (2m) is particularly non-trivial as it is substantially more reactive toward electrophiles or oxidation. The proposed HAT mechanism was further supported by the formation of a radical cyclization product (3n). A head-to-head comparison was then made between the new protocol and the acid-mediated process. While subjecting diene $\mathbf{2 0}$ to conventional conditions only produced a complex mixture containing degradation products derived from ether bond cleavage, the Cocatalyzed method smoothly afforded selective mono-hydroamidation on the more accessible alkene moiety.

We continued looking into the chemoselectivity with particular emphasis on acid-sensitive protecting groups, for instance, ketal and $N$-Boc groups (Scheme 2c, 3p, q). Additional examples were tested containing ketones, epoxides, six- and five-membered heterocycles (3r-u). Excellent compatibility was observed in all cases. In the presence of a homoallylic hydroxy group, dihydrooxazine was initially formed via intramolecular nitrilium trapping, which opened up to give the amide product in high yield upon basic aqueous workup (3v). 


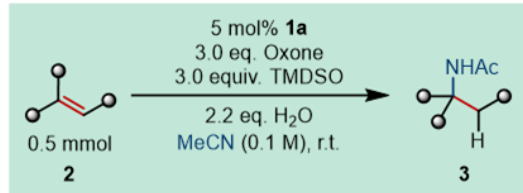

b. Chemoselective Activation

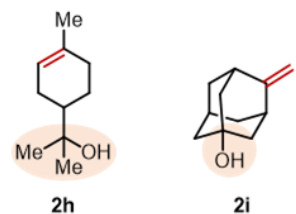

$\int_{\mathrm{Me}}^{\mathrm{OH}}$

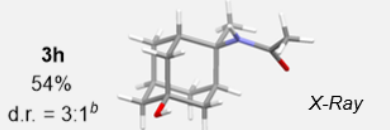

a. Evaluation of Olefin Substitution

$\mathrm{H}_{\mathrm{H}_{9}^{\mathrm{Me}}}^{\mathrm{Me}} \sim_{\mathrm{Me}}^{\mathrm{Me}}$

$$
\begin{array}{llllllll}
2 \mathrm{a} & 2 \mathrm{~b} & 2 \mathrm{c} & 2 \mathrm{~d} & 2 \mathrm{e} & 2 \mathrm{f} & 2 \mathrm{~g}
\end{array}
$$

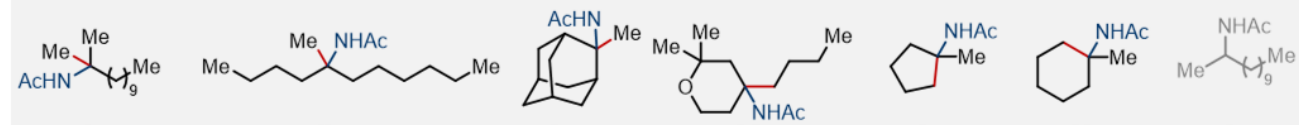
$\begin{array}{lll}3 \mathbf{a} & \mathbf{3 b} & 3 \mathbf{c} \\ 94 \% & 96 \% & 95 \%\end{array}$ $\begin{array}{cc}3 \mathrm{c} & 3 \mathbf{d} \\ 95 \% & 65 \%\end{array}$

$3 e$
$86 \%$ $3 f$
$69 \%$ $<10 \%$

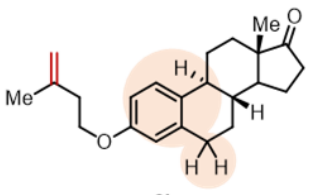

2j
$\overbrace{\mathrm{O}}^{\mathrm{O}} \mathrm{N}_{\mathrm{B}}^{\mathrm{B}} \mathrm{Bu}_{\mathrm{Me}}$

21

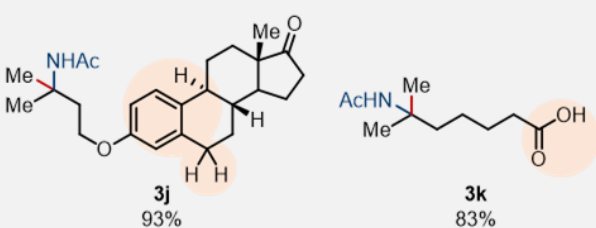

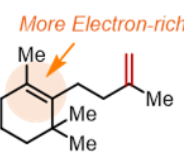

$2 \mathrm{~m}$
(1)

2 n
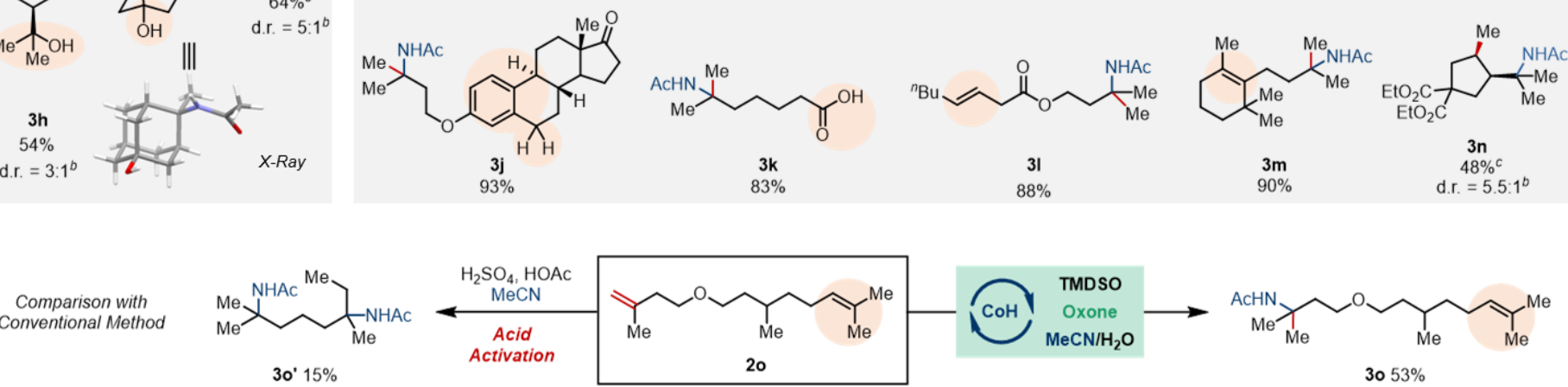

c. Functional Group Compatibility

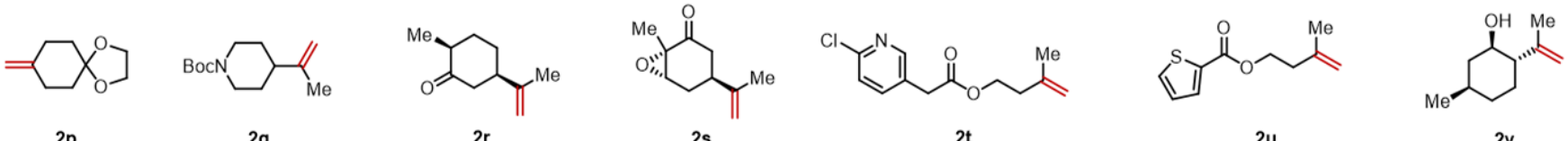

$2 p$<smiles>CC(C)NC1(C)CCC2(CCN(C(C)(C)C)CCO2)CC1</smiles>

$3 \mathbf{p}^{d}$
$85 \%$

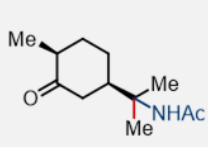

$3 \mathbf{r}$
$95 \%$

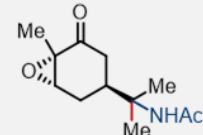

$\underbrace{\mathrm{C}}_{\mathrm{O}} \overbrace{\mathrm{Me}}^{\mathrm{MeC}}$

$3 \mathbf{t}$

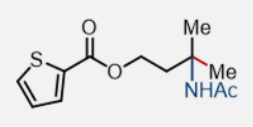

$3 \mathbf{u}$
$95 \%$

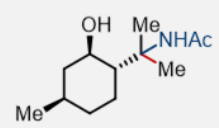

$3 v$
$95 \%$

d. Nitrile as a Reagent

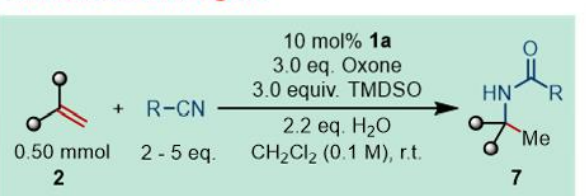

2

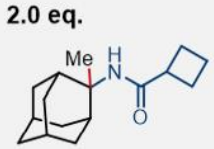

$7 a^{e}, 70 \%$

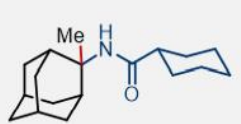

$7 b^{e}, 65 \%$

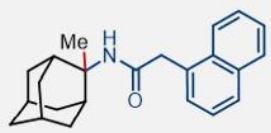

$7 c^{e}, 58 \%$

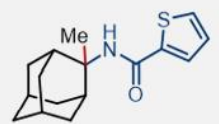

$7 d^{e}, 57 \%$
$5.0 \mathrm{eq}$. $7 e^{f}, 51 \%$

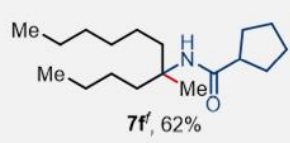<smiles>CCCCCCC([N])(CCCCC)NC(=O)C1CC1</smiles>

$7 \mathbf{g}^{\prime}, 70 \%$<smiles>CCCCCCC(C)(CCCC)NC(=O)C(C)[N+](=O)[O-]</smiles>

$7 h^{f}, 45 \%$

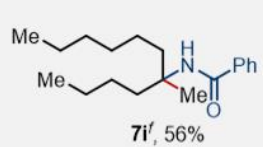

$7 i^{f}, 56 \%$

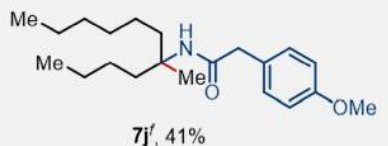

Scheme 2. Scope of the Co-Catalyzed Hydroamidation. ${ }^{a}$ Unless noted otherwise, yields correspond to isolated, analytically pure material. Conditions: 2 ( $0.50 \mathrm{mmol}), \mathbf{1 a}(5 \mathrm{~mol} \%)$, oxone (3.0 equiv.), TMDSO 
(3.0 equiv.), $\mathrm{H}_{2} \mathrm{O}$ (2.2 equiv.) in $5.0 \mathrm{~mL} \mathrm{MeCN}$ at r.t. for $18 \mathrm{~h} .{ }^{b}$ Determined by ${ }^{1} \mathrm{H} \mathrm{NMR}$ analysis of the crude reaction mixture. ${ }^{c}$ Isolated yield of the major diastereomer. ${ }^{d}$ With additional 2,6-lutidine (2.0 equiv). ${ }^{e} \mathbf{2}(0.50 \mathrm{mmol}), \mathrm{RCN}$ ( $\left.1 \mathrm{mmol}\right), \mathbf{1 a}(10 \mathrm{~mol} \%)$, oxone (3.0 equiv.), TMDSO (3.0 equiv.), $\mathrm{H}_{2} \mathrm{O}$ (2.2 equiv.) in $5.0 \mathrm{~mL} \mathrm{CH} \mathrm{Cl}_{2}$ at r.t. for 18 h. ${ }^{f} \mathbf{2}(0.50 \mathrm{mmol}), \mathrm{RCN}(2.5 \mathrm{mmol}), \mathbf{1 a}(10 \mathrm{~mol} \%)$, oxone (3.0 equiv.), TMDSO (3.0 equiv.), $\mathrm{H}_{2} \mathrm{O}$ (2.2 equiv.) in $5.0 \mathrm{~mL} \mathrm{CH}_{2} \mathrm{Cl}_{2}$ at r.t. for $18 \mathrm{~h}$.

Whereas the result shown above are encouraging, we were aware of the severe limitation of using solvent-quantities of nitriles, which the vast majority of the examples regarding Ritter-type amidation relies on. It has proven quite difficult to use nitriles as a reagent, even in large excess. ${ }^{[10 c]}$ Nonetheless, a few groups including our own have recently collected evidence supporting the intermediacy of organocobalt(IV) species in oxidative hydrofunctionalization reactions. ${ }^{[12 a, 18 d, 19 b]}$ Thus, we wondered if such species, though likely being extremely short-lived due to the weak $3^{\circ}$ alkyl-Co bond, could still effect some control on the generation of the carbocations. ${ }^{[20]}$ Such a process might enable the desired transformation at a lower concentration of the nucleophile.

To our delight, switching to dichloromethane as the solvent, a modified protocol was found amenable for hydroamination using reagent-quantities of the nitriles. Although excess nitrile (2-5 equiv.) was still necessary for obtaining decent yields, this has allowed us to explore a variety of nitriles for $\alpha$-tertiary amide synthesis (Scheme 2d). Alkyl, aryl, and heteroaryl nitriles were all found suitable for the hydroamidation. Either an increase in the steric bulk of the nitrile or a decrease in the catalyst loading led to diminished yields. For reactions with acyclic alkene substrates $(\mathbf{7 f}-\mathbf{j})$, the remaining mass balance was primarily isomerized alkene. As a case of extreme steric congestion, a formidable amide linking two adamantyl groups was synthesized in over $50 \%$ yield $(\mathbf{7 e})$. 


\section{Gram-scale experiment}

To further demonstrate the synthetic utility of this new protocol, we targeted aminoadamantane derivative 8, an intermediate en route to a Rho kinase inhibitor (Scheme 3). ${ }^{[21]}$ The adamantane structure has been extensively employed as a lipophilic "add-on" for pharmacophore modification, which improves the pharmacokinetics of a drug. Monofunctional adamantane building blocks are readily available through carbocation chemistry. In contrast, the synthesis of equally important bifunctional analogs like $\mathbf{8}$ often involves protecting group manipulations or hazardous materials (e.g. azides). ${ }^{[2]}$

To this, we show that the gram-scale hydroamidation of $\mathbf{2 i}$ proceeded smoothly under the standard conditions. The major diastereomer of the resulting amide $3 \mathbf{i}$ was isolated in decent yield, which was converted to the free amine $\mathbf{8}$ upon basic hydrolysis. This provides a more rapid alternative to the literature route, where a mixture of diastereomers was delivered through a multi-step sequence involving silyl protecting groups, cryogenic operations, and stoichiometric Ti(IV) salts.

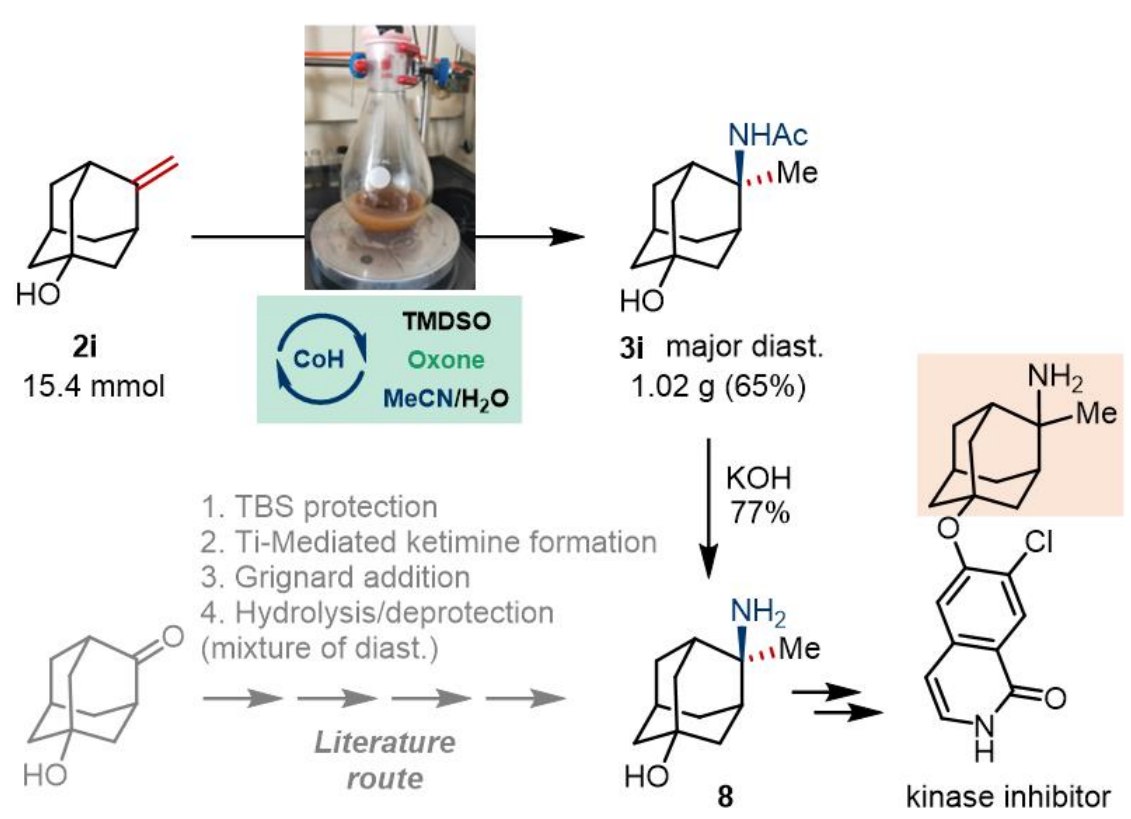


Scheme 3. Gram-Scale Hydroamidation and Application.

\section{$\underline{\text { Mechanistic studies }}$}

A set of deuterium-labeling experiments were performed to shed light on the mechanism of this reaction (Scheme 4). First, $\mathrm{PhSiD}_{3}$ was employed in place of TMDSO in the hydroamidation reaction of $2 \mathbf{u}$ (Scheme 4a). At the outset, $127 \% \mathrm{D}$ was incorporated at $\mathrm{C}\left(\mathrm{a}, \mathrm{a}^{\prime}\right)$ of $\mathbf{3} \mathbf{u}$, confirming that the silane serves as the hydride source for HAT. Deuterium incorporation of higher than $100 \%$ supports equilibrium intermediacy of an alkene after HAT that causes H/D scrambling. Similar observations were made in related Mn-catalyzed hydrogenation reactions reported by Shenvi. ${ }^{[22]}$ No $D$ was found at $C(b)$, indicating neglectable HAT of trisubstituted alkene $4 \mathbf{u}$. The reaction in the presence of a large excess of $\mathrm{D}_{2} \mathrm{O}$ produced corresponding acetamide $\mathbf{3} \mathbf{w}$ and isomerized olefin $\mathbf{4} \mathbf{w}$ without detectable deuteration at any carbons (Scheme 4b). This suggests the absence of proton-mediated alkene activation in the formation of either product, which corroborates the control experiment results shown in Table 1 and excellent chemoselectivity observed.

Next, we carried out a crossover reaction using a mixture of $\mathbf{2 w}-\mathrm{d}_{4}$ and $\mathbf{2 c}$ (Scheme $\left.4 \mathrm{c}\right)$. A substantial amount of the alkene isomer $\mathbf{4 w}$ was formed under these conditions, and deuterium crossover was detected in the amide product $3 \mathbf{c}(8 \% \mathrm{D}$ at $\mathrm{C}(\mathrm{a}))$. This indicates the involvement of $\mathrm{Co}-\mathrm{D}$ species, which is likely derived from the HAT-type isomerization of $2 \mathbf{w}-\mathrm{d}_{4}$.

Finally, it is noted that carbocation deprotonation might be an alternative or co-existing pathway for isomerization, which has been proposed to account for the different reaction outcomes observed in Cocatalyzed alkene isomerizations under redox-neutral and oxidative conditions. ${ }^{[23]}$ To probe this possibility, 
we performed the reactions with varying amounts of the nitrile (Scheme 4d). Full conversion of $\mathbf{2} \mathbf{w}$ was reached and a good mass balance was achieved in each reaction. A strong positive correlation was observed between the concentration of the nuclephile and the yield of the desired transformation $(\mathbf{3 x})$ over isomerization (4w). This implies that while HAT-type isomerization exists, $\mathbf{3} \mathbf{x}$ and a significant portion of $4 \mathbf{w}$ could be derived from a common intermediate, either a carbocation or its equivalent. 
a) With Deuterium-Labeled Silane

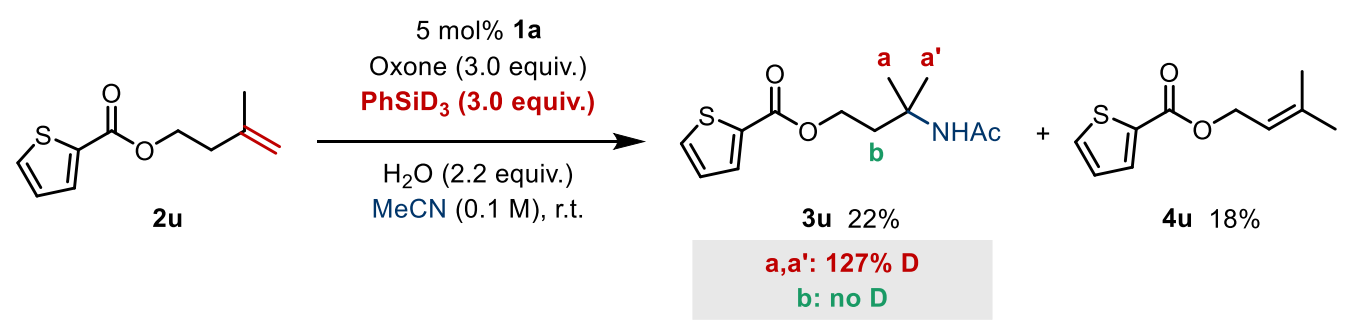

b) Test for Proton-Activation

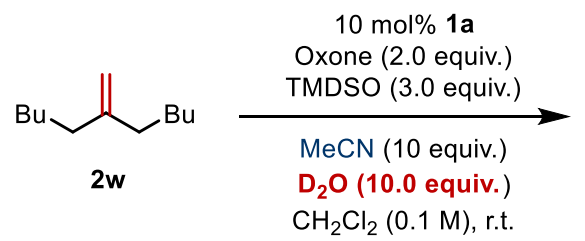

c) Crossover Reaction

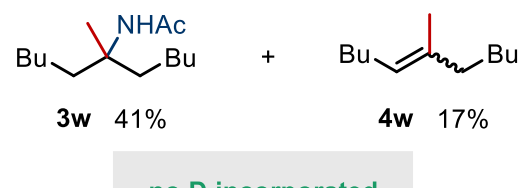

no D incorporated

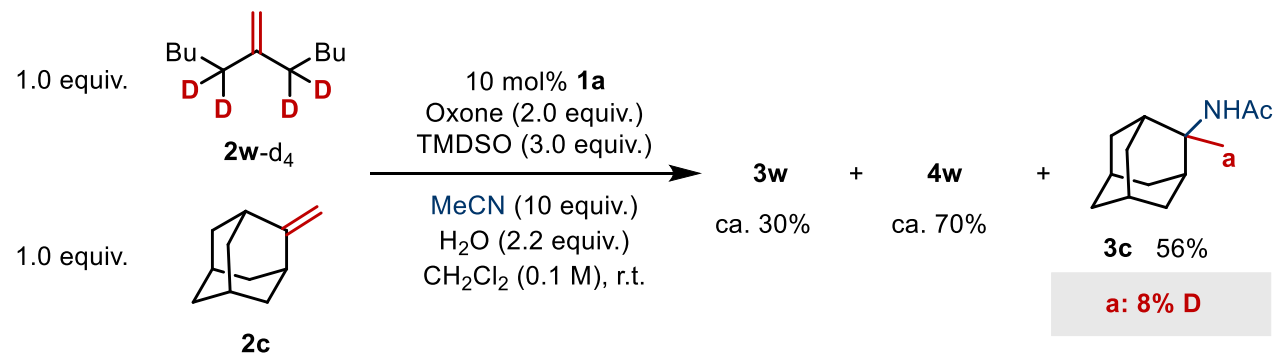

d) Effect of the Amount of Nitrile

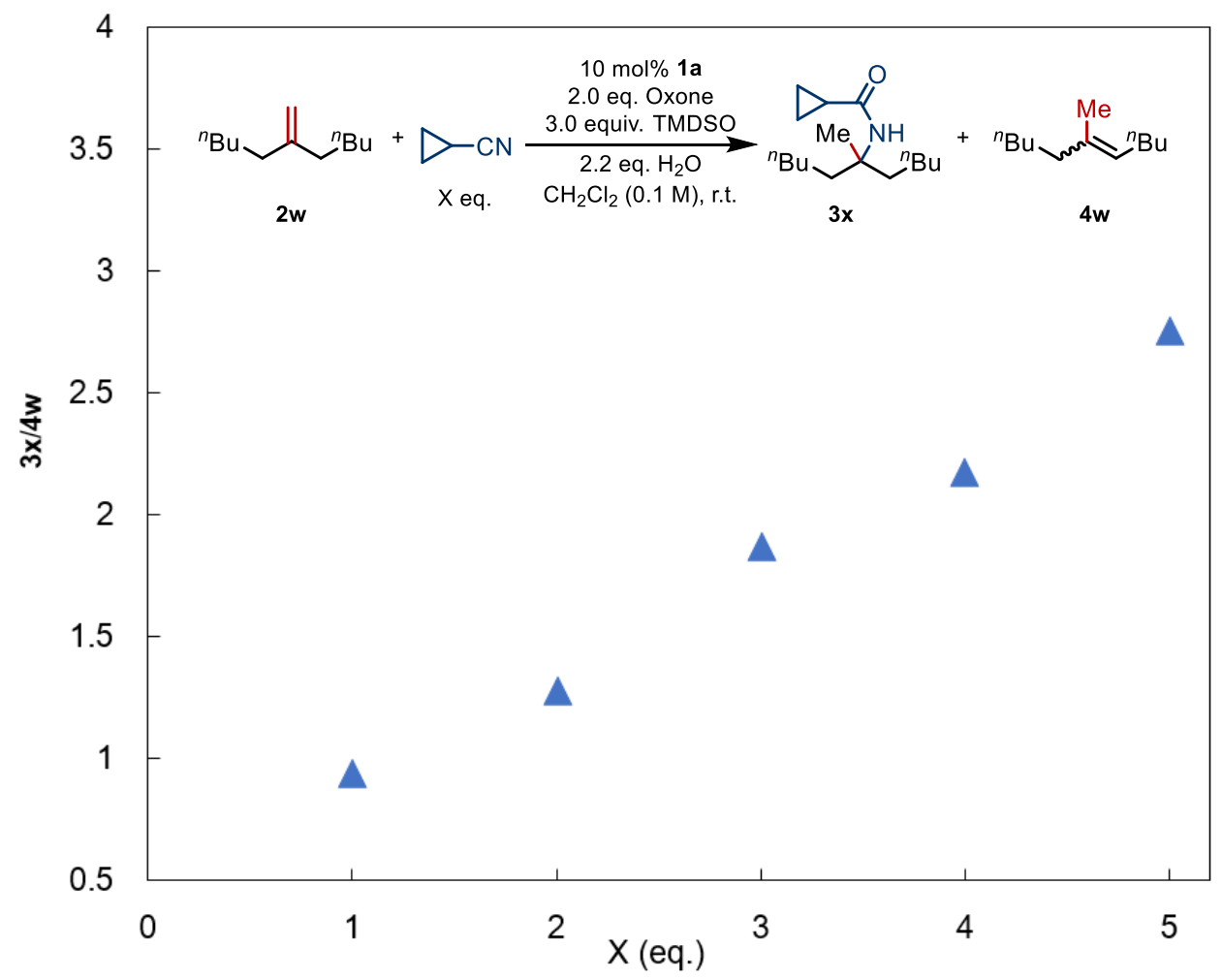

Scheme 4. Mechanistic Investigation. 
A plausible catalytic cycle is depicted in Scheme 5. The persulfate could serve as a two-electron oxidant to deliver a $\mathrm{Co}(\mathrm{III})-\mathrm{OH}$ species 9 and a cationic $\mathrm{Co}(\mathrm{III})$ complex 10. The former reacts with a silane to give a $\mathrm{Co}-\mathrm{H}$ species 11, which undergoes $\mathrm{HAT}$ with an alkene $\mathbf{2}$ in a reversible fashion. The resulting tertiary radical $\mathbf{1 2}$ might be trapped to form an organocobalt species $\mathbf{1 3}$ containing a very weak Co- $\mathrm{C}$ bond. Oxidation of either $\mathbf{1 2}$ or $\mathbf{1 3}$ by the cationic species $\mathbf{1 0}$ would effect radical-polar crossover to generate the corresponding carbocation $\mathbf{1 4}$, which is subsequently trapped by a nitrile in the presence of water to complete the amidation. The alkene isomerization could take place from either radical $\mathbf{1 2}$ or carbocation $\mathbf{1 4}$, via HAT or deprotonation, respectively.

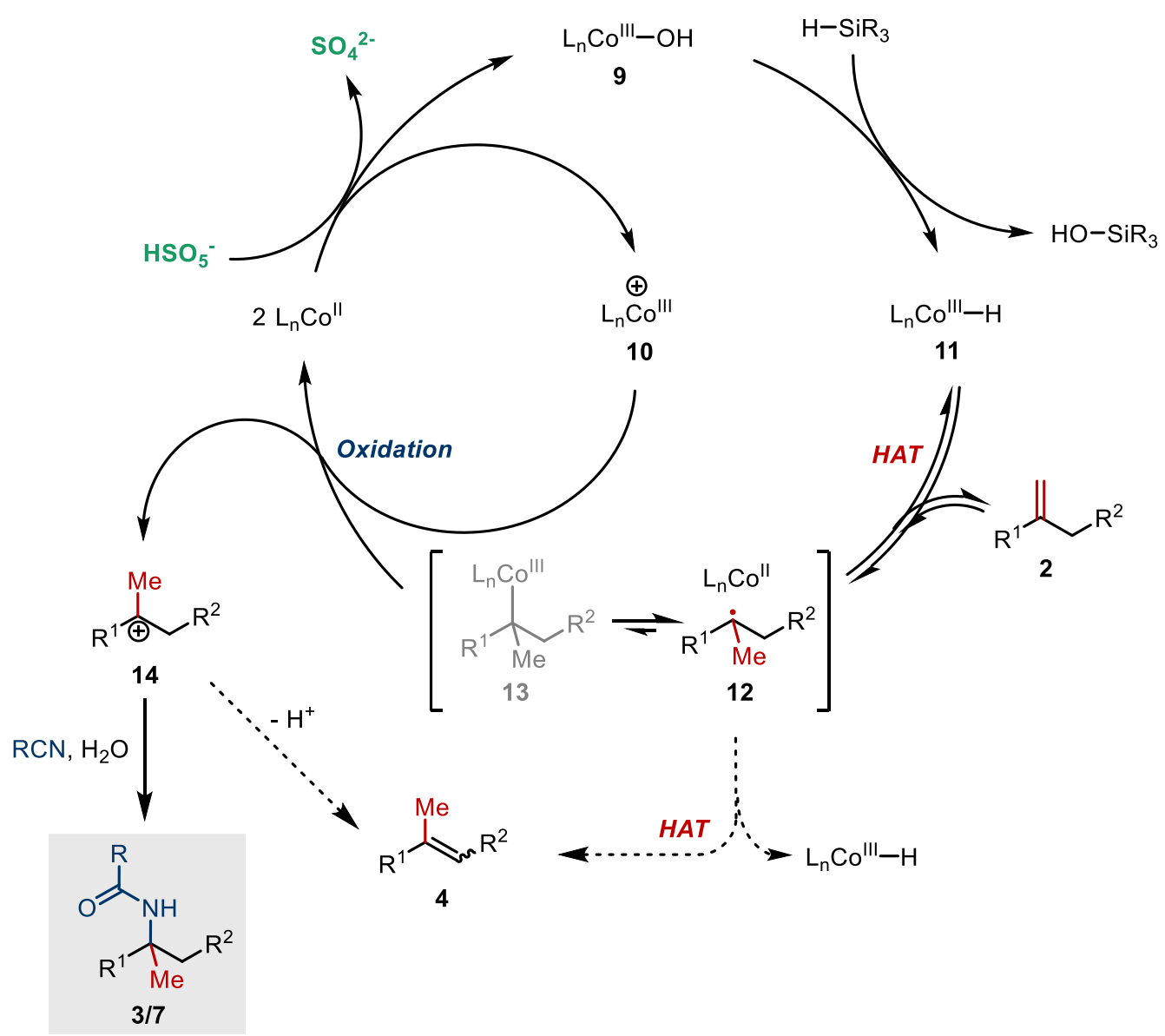

Scheme 5. Proposed Catalytic Cycle. 


\section{Conclusion}

In conclusion, we have developed a general and scalable Co-catalyzed hydroamidation protocol using unactivated alkenes and nitriles of either solvent- or reagent-quantities. An optimal system composed of CoSalen/oxone/silane was found crucial to enable efficient HAT followed by oxidative functionalization of the resulting $3^{\circ}$ alkyl radical intermediates, which delivers a wide range of $\alpha$-tertiary amides with excellent chemoselectivity. This method provides an alternative approach towards challenging amides that are difficult to access due to steric hindrance or sensitive functional groups.

\section{Methods}

General Procedures for Cobalt-Catalyzed Intermolecular Oxidative Hydroamidation. An ovendried $25 \mathrm{~mL}$ re-sealable schlenk tube equipped with a Teflon-coated magnetic stir bar was charged with Co catalyst 1a (15 mg, $0.025 \mathrm{mmol}, 0.05$ equiv.) and oxone (100 mesh, $922.2 \mathrm{mg}, 1.5 \mathrm{mmol}, 3.0$ equiv.). The reaction vessel was then briefly evacuated and backfilled with nitrogen (this sequence was repeated a total of three times). Anhydrous acetonitrile ( $5.0 \mathrm{~mL}), 2$ ( $0.50 \mathrm{mmol}, 1.0$ equiv.), $\mathrm{H}_{2} \mathrm{O}(20 \mu \mathrm{L}, 1.1 \mathrm{mmol}$, 2.2 equiv.) and 1,1,3,3-tetramethyldisiloxane ( $275 \mu \mathrm{L}, 1.5 \mathrm{mmol}, 3.0$ equiv.) were added to the reaction vessel via syringe sequentially. The reaction mixture was stirred at r.t. for $18 \mathrm{~h}$. The mixture was filtered through a short pad of silica gel with $\mathrm{CH}_{2} \mathrm{Cl}_{2} / \mathrm{MeOH}(20 / 1)$ as an eluent. The solvents were removed in vacuo and the residue was purified by silica gel column chromatography to afford amide product 3 .

An oven-dried $25 \mathrm{~mL}$ re-sealable schlenk tube equipped with a Teflon-coated magnetic stir bar was charged with Co catalyst 1a (30 mg, 0.05 mmol, 0.1 equiv.) and oxone (100 mesh, $922.2 \mathrm{mg}, 1.5 \mathrm{mmol}$, 3.0 equiv.). The reaction vessel was then briefly evacuated and backfilled with nitrogen (this sequence was repeated a total of three times). Anhydrous dichloromethane $(5.0 \mathrm{~mL})$, nitrile $(1.0 \mathrm{mmol}$ or $2.5 \mathrm{mmol})$, 
2 (0.50 mmol, 1.0 equiv.), $\mathrm{H}_{2} \mathrm{O}(20 \mu \mathrm{L}, 1.1 \mathrm{mmol}, 2.2$ equiv.) and 1,1,3,3-tetramethyldisiloxane (275 $\mu \mathrm{L}$, $1.5 \mathrm{mmol}, 3.0$ equiv.) were added to the reaction vessel via syringe sequentially. The reaction mixture was stirred at r.t. for $18 \mathrm{~h}$. The mixture was filtered through a short pad of silica gel with $\mathrm{CH}_{2} \mathrm{Cl}_{2} / \mathrm{MeOH}(20 / 1)$ as an eluent. The solvents were removed in vacuo and the residue was purified by silica gel column chromatography to afford amide product 7.

\section{Data availability}

The authors declare that all other data supporting the findings of this study are available within the article and Supplementary Information files, and also are available from the corresponding author upon reasonable request.

\section{Acknowledgements}

Financial support was provided by the Natural Science Foundation of China (21901011), and startup fund from the College of Chemistry and Molecular Engineering, Peking University and BNLMS. The authors would like to thank Dr. Xiaoge Wang (PKU) for X-ray crystallography.

\section{Author contributions}

R. Z. designed the experiments. Y.-N. Y., R.-Q. D., D.-C. O., and Q. Z. performed the experiments. R. Z. and Y.-N. Y. prepared this manuscript and the supplementary information.

\section{Competing financial interests}


The authors declare no competing financial interests.

\section{References}

1 (a) He, S.; Ye, Z.; Dobbelaar, P. H.; Sebhat, I. K.; Guo, L.; Liu, J.; Jian, T.; Lai, Y.; Franklin, C. L.; Bakshi, R. K.; Dellureficio, J. P.; Hong, Q.; Tsou, N. N.; Ball, R. G.; Cashen, D. E.; Martin, W. J.; Weinberg, D. H.; Macneil, T.; Tang, R.; Tamvakopoulos, C.; Peng, Q.; Miller, R. R.; Stearns, R. A.; Chen, H. Y.; Chen, A. S.; Strack, A. M.; Fong, T. M.; Macintyre, D. E.; Wyvratt, M. J., Jr.; Nargund, R. P. Discovery of a spiroindane based compound as a potent, selective, orally bioavailable melanocortin subtype-4 receptor agonist. Bioorg. Med. Chem. Lett. 2010, 20, 2106-2110. (b) Battilocchio, C.; Baxendale, I. R.; Biava, M.; Kitching, M. O.; Ley, S. V. A flow-based synthesis of 2-aminoadamantane-2-carboxylic acid. Org. Process. Res. Dev. 2012, 16, 798-810. (c) Bouyssou, T.; Hoenke, C.; Rudolf, K.; Lustenberger, P.; Pestel, S.; Sieger, P.; Lotz, R.; Heine, C.; Büttner, F. H.; Schnapp, A.; Konetzki, I. Discovery of olodaterol, a novel inhaled $\beta_{2}$-adrenoceptor agonist with a 24 h bronchodilatory efficacy. Bioorg. Med. Chem. Lett. 2010, 20, 1410-1414. (d) Hager, A.; Vrielink, N.; Hager, D.; Lefranc, J.; Trauner, D. Synthetic approaches towards alkaloids bearing $\alpha$-tertiary amines. Nat. Prod. Rep. 2016, 33, 491-522.

2 Wanka, L.; Iqbal, K.; Schreiner, P. R. The lipophilic bullet hits the targets: medicinal chemistry of adamantane derivatives. Chem. Rev. 2013, 113, 3516-3604.

3 Bloch, R. Additions of organometallic reagents to $\mathrm{C}=\mathrm{N}$ bonds: reactivity and selectivity. Chem. Rev. 1998, 98, 1407-1438.

4 Clayden, J.; Donnard, M.; Lefranc, J.; Tetlow, D. J. Quaternary centres bearing nitrogen (alphatertiary amines) as products of molecular rearrangements. Chem. Commun. 2011, 47, 4624-4639.

5 (a) Sharma, A.; Hartwig, J. F. Metal-catalysed azidation of tertiary C-H bonds suitable for late-stage functionalization. Nature 2015, 517, 600-604. (b) Kainz, Q. M.; Matier, C. D.; Bartoszewicz, A.; Zultanski, S. L.; Peters, J. C.; Fu, G. C. Asymmetric copper-catalyzed C-N cross-couplings induced by visible light. Science 2016, 351, 681-684. (c) Zhdankin, V. V.; Krasutsky, A. P.; Kuehl, C. J.; Simonsen, A. J.; Woodward, J. K.; Mismash, B.; Bolz, J. T. Preparation, X-ray crystal structure, and chemistry of stable azidoiodinanes derivatives of benziodoxole. J. Am. Chem. Soc. 1996, 118, 5192-5197. (d) Waser, J.; Gaspar, B.; Nambu, H.; Carreira, E. M. Hydrazines and azides via the metal-catalyzed hydrohydrazination and hydroazidation of olefins. J. Am. Chem. Soc. 2006, 128, 11693-11712. (e) Yu, X. L.; Chen, J. R.; Chen, D. Z.; Xiao, W. J. Vi8sible-light-induced photocatalytic azotrifluoromethylation of alkenes with aryldiazonium salts and sodium triflinate. Chem. Commun. 2016, 52, 8275-8278. (f) Zhu, Y.; Li, X.; Wang, X.; Huang, X.; Shen, T.; Zhang, Y.; Sun, X.; Zou, M.; Song, S.; Jiao, N. Silver-catalyzed decarboxylative azidation of aliphatic carboxylic acids. Org. Lett. 2015, 17, 4702-4705. (g) Wang, Y.; Li, G. X.; Yang, G.; He, G.; Chen, G. A visible-light-promoted radical reaction system for azidation and halogenation of tertiary aliphatic C-H bonds. Chem. Sci. 2016, 7, 2679-2683. (h) Gui, J.; Pan, C. M.; Jin, Y.; Qin, T.; Lo, J. C.; Lee, B. J.; Spergel, S. H.; Mertzman, M. E.; Pitts, W. J.; La Cruz, T. E.; Schmidt, M. A.; Darvatkar, N.; Natarajan, S. R.; Baran, P. S. Practical olefin hydroamination with nitroarenes. Science 2015, $348,886-891$. 
Schafer, G.; Matthey, C.; Bode, J. W. Facile synthesis of sterically hindered and electron-deficient secondary amides from isocyanates. Angew. Chem. Int. Ed. 2012, 51, 9173-9175.

7 (a) Jiang, D.; He, T.; Ma, L.; Wang, Z. Recent developments in Ritter reaction. RSC Adv. 2014, 4, 64936-64946. (b) Guérinot, A.; Reymond, S.; Cossy, J. Ritter reaction: recent catalytic developments. Eur. J. Org. Chem. 2012, 2012, 19-28.

8 (a) Michaudel, Q.; Thevenet, D.; Baran, P. S. Intermolecular Ritter-type C-H amination of unactivated $\mathrm{sp}^{3}$ carbons. J. Am. Chem. Soc. 2012, 134, 2547-2550. (b) Xiang, J.; Shang, M.; Kawamata, Y.; Lundberg, H.; Reisberg, S. H.; Chen, M.; Mykhailiuk, P.; Beutner, G.; Collins, M. R.; Davies, A.; Del Bel, M.; Gallego, G. M.; Spangler, J. E.; Starr, J.; Yang, S.; Blackmond, D. G.; Baran, P. S. Hindered dialkyl ether synthesis with electrogenerated carbocations. Nature 2019, 573, 398-402.

9 (a) Sakaguchi, S.; Hirabayashi, T.; Ishii, Y. First Ritter-type reaction of alkylbenzenes using $N$ hydroxyphthalimide as a key catalyst. Chem. Commun. 2002, 516-517. (b) Kiyokawa, K.; Takemoto, K.; Minakata, S. Ritter-type amination of C-H bonds at tertiary carbon centers using iodic acid as an oxidant. Chem. Commun. 2016, 52, 13082-13085. (c) Kiyokawa, K.; Watanabe, T.; Fra, L.; Kojima, T.; Minakata, S. Hypervalent iodine(III)-mediated decarboxylative Ritter-type amination leading to the production of alpha-tertiary amine derivatives. J. Org. Chem. 2017, 82, 11711-11720. (d) Duhamel, T.; Martínez, M. D.; Sideri, I. K.; Muñiz, K. 1,3-Diamine formation from an interrupted Hofmann-Löffler reaction: iodine catalyst turnover through Ritter-type amination. ACS Catal. 2019 , 9, 7741-7745.

10 (a) Yasu, Y.; Koike, T.; Akita, M. Intermolecular aminotrifluoromethylation of alkenes by visiblelight-driven photoredox catalysis. Org. Lett. 2013, 15, 2136-2139. (b) Fumagalli, G.; Boyd, S.; Greaney, M. F. Oxyarylation and aminoarylation of styrenes using photoredox catalysis. Org. Lett. 2013, 15, 4398-4401. (c) Hari, D. P.; Hering, T.; Konig, B. The photoredox-catalyzed Meerwein addition reaction: intermolecular amino-arylation of alkenes. Angew. Chem. Int. Ed. 2014, 53, 725-728. (d) Qian, B.; Chen, S.; Wang, T.; Zhang, X.; Bao, H. Iron-catalyzed carboamination of olefins: synthesis of amines and disubstituted beta-amino acids. J. Am. Chem. Soc. 2017, 139, 13076-13082.

11 (a) Zhang, Z.; Lee, S. D.; Widenhoefer, R. A. Intermolecular hydroamination of ethylene and 1alkenes with cyclic ureas catalyzed by achiral and chiral gold(I) complexes. J. Am. Chem. Soc. 2009, 131, 5372-5373. (b) Sevov, C. S.; Zhou, J.; Hartwig, J. F. Iridium-catalyzed intermolecular hydroamination of unactivated aliphatic alkenes with amides and sulfonamides. J. Am. Chem. Soc. 2012, 134, 11960-11963. (c) Zhou, Y.; Engl, O. D.; Bandar, J. S.; Chant, E. D.; Buchwald, S. L. $\mathrm{CuH}$-catalyzed asymmetric hydroamidation of vinylarenes. Angew. Chem. Int. Ed. 2018, 57, 6672-6675. (d) Yu, F.; Chen, P.; Liu, G. Pd(II)-catalyzed intermolecular enantioselective hydroamination of styrenes. Org. Chem. Front. 2015, 2, 819-822. (e) Huang, L.; Arndt, M.; Goossen, K.; Heydt, H.; Goossen, L. J. Late transition metal-catalyzed hydroamination and hydroamidation. Chem. Rev. 2015, 115, 2596-2697.

12 (a) Zhou, X. -L.; Yang, F.; Sun, H. -L.; Yin, Y. -N.; Ye, W. -T.; Zhu, R. Cobalt-catalyzed intermolecular hydrofunctionalization of alkenes: evidence for a bimetallic pathway. J. Am. Chem. Soc. 2019, 141, 7250-7255. (b) Sun, H. -L.; Yang, F.; Ye, W. -T.; Wang, J. -J.; Zhu, R. Dual cobalt and photoredox catalysis enabled intermolecular oxidative hydrofunctionalization. ACS Catal. 2020, 10, 4983-4989. (c) Zhu, R. Emerging catalyst control in cobalt-catalyzed oxidative hydrofunctionalization reactions. Synlett 2019, 30, 2015-2021. 
13 Isayama, S.; Mukaiyama, T. A new method for preparation of alcohols from olefins with molecular oxygen and phenylsilane by the use of bis(acetylacetonato)cobalt(II). Chem. Lett. 1989, 18, 1071-1074.

14 Waser, J.; Nambu, H.; Carreira, E. M. Cobalt-catalyzed hydroazidation of olefins: convenient access to alkyl azides. J. Am. Chem. Soc. 2005, 127, 8294-8295.

15 Li, G.; Kuo, J. L.; Han, A.; Abuyuan, J. M.; Young, L. C.; Norton, J. R.; Palmer, J. H. Radical isomerization and cycloisomerization initiated by $\mathrm{H} \cdot$ transfer. J. Am. Chem. Soc. 2016, 138, 7698-7704.

16 Crossley, S. W.; Barabe, F.; Shenvi, R. A. Simple, chemoselective, catalytic olefin isomerization. $J$. Am. Chem. Soc. 2014, 136, 16788-16791.

17 Ma, X.; Herzon, S. B. Intermolecular hydropyridylation of unactivated alkenes. J. Am. Chem. Soc. 2016, 138, 8718-8721.

18 For selected examples: (a) Shigehisa, H.; Aoki, T.; Yamaguchi, S.; Shimizu, N.; Hiroya, K. Hydroalkoxylation of unactivated olefins with carbon radicals and carbocation species as key intermediates. J. Am. Chem. Soc. 2013, 135, 10306-10309. (b) Shigehisa, H.; Hayashi, M.; Ohkawa, H.; Suzuki, T.; Okayasu, H.; Mukai, M.; Yamazaki, A.; Kawai, R.; Kikuchi, H.; Satoh, Y.; Fukuyama, A.; Hiroya, K. Catalytic synthesis of saturated oxygen heterocycles by hydrofunctionalization of unactivated olefins: unprotected and protected strategies. J. Am. Chem. Soc. 2016, 138, 10597-10604. (c) Shigehisa, H.; Kikuchi, H.; Hiroya, K. Markovnikov-selective addition of fluorous solvents to unactivated olefins using a Co catalyst. Chem. Pharm. Bull. 2016, 64, 371-374. (d) Ebisawa, K.; Izumi, K.; Ooka, Y.; Kato, H.; Kanazawa, S.; Komatsu, S.; Nishi, E.; Shigehisa, H. Catalyst- and silane-controlled enantioselective hydrofunctionalization of alkenes by cobalt-catalyzed hydrogen atom transfer and radical-polar crossover. J. Am. Chem. Soc. 2020, 142, 13481-13490. (e) Shigehisa, H.; Ano, T.; Honma, H.; Ebisawa, K.; Hiroya, K. Co-catalyzed hydroarylation of unactivated olefins Org. Lett. 2016, 18, 3622-3625.

19 For selected examples: (a) Touney, E. E.; Foy, N. J.; Pronin, S. V. Catalytic radical-polar crossover reactions of allylic alcohols. J. Am. Chem. Soc. 2018, 140, 16982-16987. (b) Discolo, C. A.; Touney, E. E.; Pronin, S. V. Catalytic asymmetric radical-polar crossover hydroalkoxylation. J. Am. Chem. Soc. 2019, 141, 17527-17532. (c) Lo, J. C.; Kim, D.; Pan, C. M.; Edwards, J. T.; Yabe, Y.; Gui, J.; Qin, T.; Gutierrez, S.; Giacoboni, J.; Smith, M. W.; Holland, P. L.; Baran, P. S. Fe-catalyzed C-C bond construction from olefins via radicals. J. Am. Chem. Soc. 2017, 139, 2484-2503. (d) Shepard, S. M.; Diaconescu, P. L. Redox-switchable hydroelementation of a cobalt complex supported by a ferrocene-based ligand. Organometallics 2016, 35, 2446-2453. (e) Yahata, K.; Kaneko, Y.; Akai, S. Cobalt-catalyzed intermolecular Markovnikov hydroamination of nonactivated olefins: $N^{2}$-selective alkylation of benzotriazole. Org. Lett. 2020, 22, 598-603. (f) Song, L.; Fu, N.; Ernst, B. G.; Lee, W. H.; Frederick, M. O.; DiStasio, R. A.; Lin, S. Dual electrocatalysis enables enantioselective hydrocyanation of conjugated alkenes. Nat. Chem. 2020, 12, 747-754. For a comprehensive review: (g) Crossley, S. W.; Obradors, C.; Martinez, R. M.; Shenvi, R. Mn-, Fe-, and Co-catalyzed radical hydrofunctionalizations of olefins. Chem. Rev. 2016, 116, 8912-9000. (h) Shevick, S. L.; Wilson, C. V.; Kotesova, S.; Kim, D.; Holland, P. L.; Shenvi, R. A. Catalytic hydrogen atom transfer to alkenes: a roadmap for metal hydrides and radicals. Chem. Sci. 2020, DOI: 10.1039/d0sc04112b. (i) Chen, J.; Shen, X.; Lu Z. Cobalt-catalyzed Markovnikov selective sequential hydrogenation/ hydrohydrazidation of aliphatic terminal alkynes. J. Am. Chem. Soc. 2020, 142, 14455-14460. (j) Shen, X.; Chen, X; Chen, J.; Sun, Y.; Cheng, Z.; Lu, Z. Ligand-promoted cobalt-catalyzed radical 
hydroamination of alkenes. Nat. Commun. 2020, 11, 783, DOI: 10.1038/s41467-020-14459-x

20 Oliver, P.; Katrin, L.; Matthias, L.; Olivier, D.; Int. Patent Appl. WO2009/156092 A2, Dec. 30, 2019.

21 Alkyl migration to ligand in a [RCo(IV)Salen $]^{+}$complex could serve as an alternative mechanism for such control, see: M. E. Vol'pin, I. Ya. Levitin, A. L. Sigan, A. T. Nikitaev. Current state of organocobalt(IV) and organorhodium(IV) chemistry. J. Organomet. Chem. 1985, 279, 263-280.

22 Obradors, C.; Martinez, R. M.; Shenvi, R. A. Ph(i-PrO) $\mathrm{SiH}_{2}$ : An exceptional reductant for metalcatalyzed hydrogen atom transfers. J. Am. Chem. Soc. 2016, 138, 4962-4971.

23 Xu, G.; Elkin, M.; Tantillo, D. J.; Newhouse, T. R.; Maimone, T. J. Traversing biosynthetic carbocation landscapes in the total synthesis of andrastin and terretonin meroterpenes. Angew. Chem. Int. Ed. 2017, 56, 12498-12502. 